Polymer Journal, Vol. 39, No. 9, pp. 961-967 (2007)

(C) 2007 The Society of Polymer Science, Japan

\title{
Cure Kinetics and Mechanical Properties of Liquid Crystalline Epoxides with Long Lateral Substituents Cured with Anhydride
}

\author{
Liyan LiAng, ${ }^{1,2,3}$ Shaoping Ren, ${ }^{1}$ Yiquan ZHENG, ${ }^{1}$ Yanxun LAN, ${ }^{1}$ and Mangeng LU ${ }^{1,3, \dagger}$ \\ ${ }^{1}$ Guangzhou Institute of Chemistry, Chinese Academy of Sciences, Guangzhou 510650, PR China \\ ${ }^{2}$ Graduate School of the Chinese Academy of Sciences, Beijing, 100080, PR China \\ ${ }^{3}$ Key Laboratory of Polymer Materials for Electronics, Guangdong, 510650, PR China
}

(Received January 22, 2007; Accepted June 19, 2007; Published July 31, 2007)

\begin{abstract}
A series of liquid crystalline (LC) epoxy monomers with different length of lateral substituents were cured with anhydrides. The cure kinetics was investigated by DSC technique. From a multi-temperature scan method, the activation energy $E_{a}$ and the frequency factor $A$ were determined and compared for epoxides with different length of lateral substituents. The results showed that as the length of lateral substituent increases, the activation energy $E_{a}$ decreases, but the curing reaction of liquid crystalline epoxides become less active and is controlled by diffusion at the late stage of curing. The phase structures and the mechanical properties of the resulted LC epoxy resins were studied by POM, WAXD, DMA, tensile tests and SEM. A nematic structure is observed. And as the length of lateral substituent increases, the cross-linking densities and glass transition temperature $\left(T_{g}\right)$ of the LC networks decreases. The tensile modulus, together with break strength and elongation at break also decreases as the side chain increasing.

[doi:10.1295/polymj.PJ2006219]
\end{abstract}

KEY WORDS Liquid Crystalline Epoxy Resin / Anhydride / Lateral Substituent / Cure Kinetics /

Epoxy resins are the most important thermosetting polymers, widely used as adhesives and composite materials ${ }^{1}$ due to the excellent chemical resistance, good thermal, electrical and mechanical properties. But they are brittle and have poor resistance to crack propagation. $^{2,3}$ The properties of epoxides can be much enhanced if liquid crystalline (LC) like structures are incorporated into epoxy networks. ${ }^{4-6}$ As compared to ordinary epoxies, crosslinked Liquid Crystalline Epoxy Resins (LCERs) show a high modulus and a very low thermal expansion. And they exhibit higher toughness due to the retardation of the crack propagation by the formation of many LC domains in the cured networks. ${ }^{7-9}$ For LC epoxides, the rigidity of mesogenic cores lead to high melting temperatures and an uncontrolled curing reaction occur after melting. Some efforts have been done to lower the melting point of Liquid Crystalline Thermsets (LCTs) and the curing temperature. It was reported that introduction of substituents into the mesogenic unity could lower the melting temperature and increase the mesophase stability. ${ }^{10,11}$

Poly-functional amines and aliphatic diacids were widely used to cure LC epoxies in the past. ${ }^{4,12-14}$ However, there are few reports on LC epoxides, especially LC epoxides with large or long lateral substituents cured with anhydride up to date. Here we report a series of LC epxides cured with anhydrides because the resulted materials have excellent thermal stability, good electrical insulation, and relatively high chemi- cal resistance. Furthermore, anhydride curing agents provide good mechanical properties with low shrinkage so they are suitable for matrices of composites for electrical applications. ${ }^{15}$

We have synthesized and characterized a series of novel LC epoxy monomers with different length of lateral substituents. ${ }^{16}$ This present paper reports the cure kinetics and mechanical properties of the LC epoxy monomers cured with an anhydride. The cure kinetics was examined by non-isothermal differential scanning calorimetry (DSC) at different heating rates. The LC textures and structure of curing products were investigated with polarized optical microscopy (POM) and Wide-angle X-ray diffraction (WAXD). And the mechanical behavior was studied by dynamic mechanical analysis (DMA), tensile test, and scanning electron microscope (SEM).

\section{EXPERIMENT}

\section{Materials}

The LC epoxy monomers, alkyl 2, 5-bis[4-(2, 3epoxypropoxy-benzoxy)]benzoate (EP-n), were synthesized according to the method reported previously. ${ }^{16}$ The hardener, 4-methylhexahydrophthalic anhydride (MHHPA), and the accelerator, benzyldimethyl -amine (BDMA) were purchased from Flucka and used as received. Their chemical structures are shown in Figure 1. The solvent, dichloromethane, was purified by standard procedures.

${ }^{\dagger}$ To whom correspondence should be addressed (Tel: +86-20-8523-2978, Fax: +86-20-8523-1119, E-mail: mglu@ gic.ac.cn). 


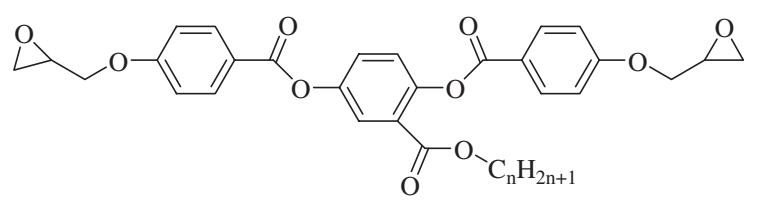

Alkyl 2,5-bis[4-(2,3-epoxypropoxy- benzoxy)]benzoate $\mathrm{EP}-\mathrm{n}, \mathrm{n}=2,6,10,14$

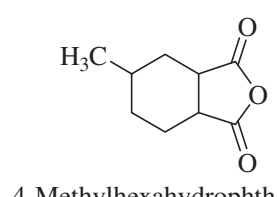

4-Methylhexahydrophthalic anhydride (MHHPA)<smiles>CN(C)Cc1ccccc1</smiles>

Benzyldimethylamine (BDMA)
Figure 1. The chemical structures of the epoxy, hardener and accelerator.

\section{Sample preparation}

The stoichiometric amount of LC epoxy monomers and MHHPA were mixed in dichloromethane, then $1 \mathrm{phr}$ of accelerator was added to system. And then the solvent was removed and dried in vacuum at room temperature. The cured samples were obtained under curing conditions showed in Table I.

\section{Measurements}

Calorimetric measurements were performed using a NETZSCH DSC 204 type calorimeter, under nitrogen atmosphere to measure the heat flow under non-isothermal conditions. The mass of samples was about 8-10 mg. The dynamic DSC tests were conducted from room temperature to $523 \mathrm{~K}$ at several heating rates under nitrogen atmosphere: $2.5,5,10,20 \mathrm{~K} / \mathrm{min}$.

The textures of the mesophases were observed with a polarizing microscope (AXIOLAB Zeiss). Wideangle X-ray diffraction (WAXD) studies were conducted on a D/max 200 X-ray.

Dynamic mechanical analysis (DMA) measurements were performed on a TA/DMA 2980 apparatus by tensile mode. Measures were run from $153 \mathrm{~K}$ to $473 \mathrm{~K}$ at the heating rate of $5 \mathrm{~K} / \mathrm{min}$ at $1 \mathrm{~Hz}$ frequency. Nitrogen was the carrier gas, with the flow rate of $30 \mathrm{~mL} / \mathrm{min}$.

Tensile tests were performed using a SHT5000 testing machine with the $2000 \mathrm{lb}$ load cell and $2 \mathrm{~mm} / \mathrm{min}$. The sample size $0.40 \times 10 \times 50 \mathrm{~mm}$ was prepared for tensile measures.
The morphologies of the fracture surfaces after tensile tests for each sample were observed using a JSM5910 scanning electron microscope (SEM) at $15 \mathrm{kV}$ accelerating voltage. Each sample was mounted on a sample holder using an electrically conductive paint as an adhesive and coated with a thin gold layer by plasma sputtering to avoid a charging effect due to non-conductive of the polymer.

\section{RESULTS AND DISCUSSION}

\section{Cure kinetics}

All kinetic studies can start with the basic equation that relates the rate of conversion at constant temperature to some function of the concentration of reactants:

$$
\frac{d \alpha}{d t}=k f(\alpha)
$$

where $d \alpha / d t$ is the rate of cure; $\alpha$ is the fractional conversion at any time $t ; k$, the Arrhenius rate constant, and $f(\alpha)$, a function form of $\alpha$ that depend on the reaction mechanism.

For non-isothermal conditions, when the temperature varies with time with a constant heating rate, $\beta=$ $d T / d t$, Equation (1) is represented as follows:

$$
\frac{d \alpha}{d T}=\frac{A}{\beta} \exp \left(-\frac{E}{R T}\right) f(\alpha)
$$

where $A$ is the frequency factor, $E$ is the activation energy, and $R$ is the gas constant.

Iso-conversional kinetic analysis offers a viable alternative in this situation. ${ }^{17,18}$ The basic idea of this type of analysis is that the reaction rate at constant extent of conversion is only a function of the temperature.

$$
\left[\frac{d \ln (d \alpha / d t)}{d T^{-1}}\right]_{\alpha}=-\frac{E_{\alpha}}{R}
$$

where $E_{\alpha}$ is the effective activation energy at a given conversion. This makes it equally effective for both the $n$th order and the autocatalytic reactions.

In practice, it is more convenient to use the integral forms of Equation (2). The derivative modes by Ozawa, Flynn and Wall, and Dole can be used to give the Ea from the plot $\ln \beta_{\mathrm{i}} v s \mathrm{~T}^{-1}{ }_{a, i}$ (here $i$ is ordinal

Table I. Curing conditions for the mixtures of EP-n/MHHPA/BDMA

\begin{tabular}{ccccccc}
\hline EP-n & $\begin{array}{c}\text { Curing } \\
\text { temperature }(\mathrm{K})\end{array}$ & $\begin{array}{c}\text { Curing } \\
\text { time }(\mathrm{h})\end{array}$ & $\begin{array}{c}\text { Mid-curing } \\
\text { temperature (K) }\end{array}$ & $\begin{array}{c}\text { Mid-curing } \\
\text { time (h) }\end{array}$ & $\begin{array}{c}\text { Post-curing } \\
\text { temperature (K) }\end{array}$ & $\begin{array}{c}\text { Post-curing } \\
\text { time }(\mathrm{h})\end{array}$ \\
\hline EP-2 & 388 & 16 & 423 & 5 & 463 & 1 \\
EP-6 & 355 & 16 & 423 & 5 & 463 & 1 \\
EP-10 & 353 & 16 & 423 & 5 & 463 & 1 \\
EP-14 & 333 & 16 & 423 & 5 & 463 & 1 \\
\hline
\end{tabular}




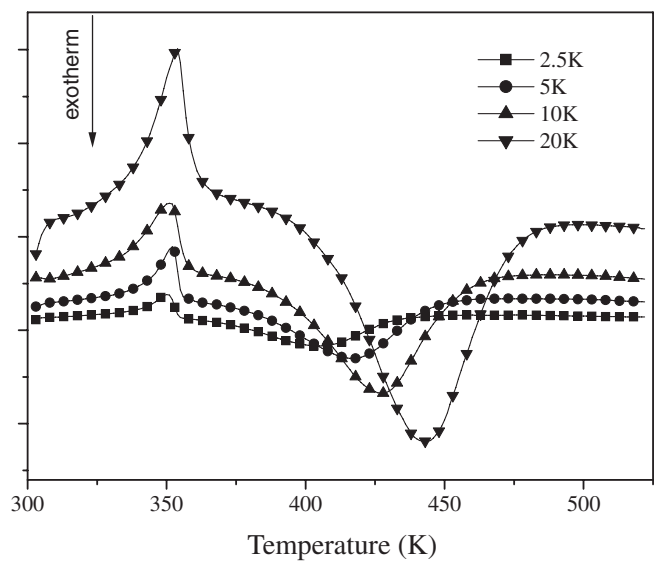

Figure 2. DSC curves for the mixture of EP-6/MHHPA/ BDMA at different heating rates.

number of DSC runs performed at different heating rate, $\beta_{i}$ ). The Ozawa mode has been used in the present computations of Ea at different $\alpha \cdot{ }^{19-21}$

The Ozawa method yields a simple relationship between the activation energy, the heating rate, and isoconversion temperature, giving the activation energy $E_{a}$ as:

$$
E_{a}=-\frac{R d \ln \beta}{1.052 d\left(1 / T_{i}\right)}
$$

where $T_{i}$ the iso-conversion temperature. The advantage here is that the activation energy can be measured over the entire course of the reaction.

Dynamic DSC scans for mixtures of EP-n/ MHHPA/BDMA were made at different heating rates $(2.5,5,10$ and $20 \mathrm{~K} / \mathrm{min})$. Typical DSC curves for EP-6 are presented in Figure 2. Similar results can be found for other epoxides with different length of lateral substituents. As can be seen in Figure 2, the melting endotherm of the mixture occurs at about $351 \mathrm{~K}$, and the exotherm due to the curing reaction follows with increasing temperature.

Figure 3 plots the conversion percent against the dynamic cure temperature at various heating rates. It shows that at the same conversion, the iso-conversion temperature, $T_{i}$, increases when the heating rate is increased.

Plots of $\ln \beta$ against $1 / T_{i}$ at different conversion have been shown in Figure 4. The fractional activation energy for the conversion from $10 \%$ to $90 \%$ can be calculated from the slope based on Equation (4), respectively. The results were summarized in Table II. The $E_{a}$ values we obtained were in reasonable agreement with results which reported in literature for epoxy/anhydride systems. ${ }^{22-25}$

From Table II, it was clear that the length of lateral substituent has great effect on $E_{a}$. The $E_{a}$ decreases with the increase of the side chain length (n) from 2

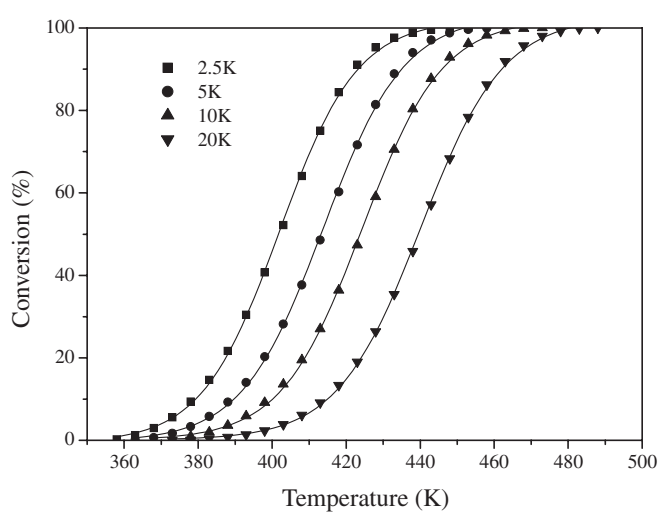

Figure 3. Plots of DSC iso-conversion temperature at different heating rates.

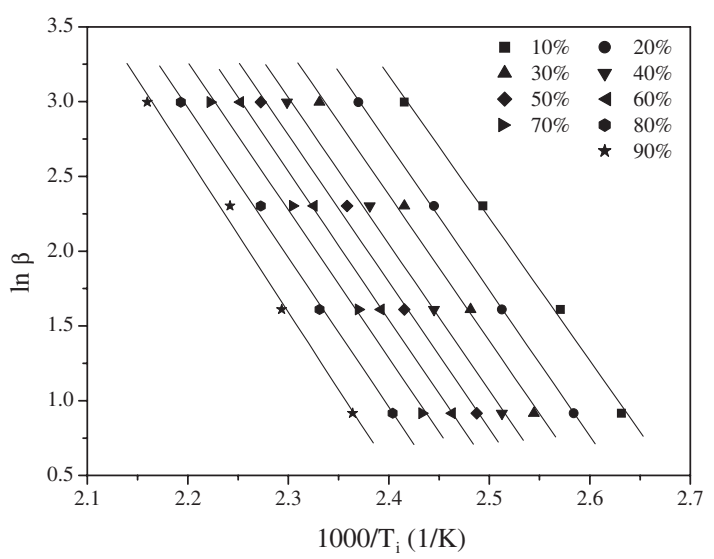

Figure 4. Plots of $\ln \beta$ against $1000 / \mathrm{T}_{\mathrm{i}}$ at different conversion to calculate the activation energy.

Table II. Activation energy as calculated by the Ozawa method

\begin{tabular}{cccccc}
\hline \multicolumn{2}{c}{ Samples } & EP-2 & EP-6 & EP-10 & EP-14 \\
\hline & $10 \%$ & 75.4 & 75.3 & 72.6 & 71.2 \\
& $20 \%$ & 79.7 & 77.1 & 75.6 & 73.2 \\
& $30 \%$ & 80.8 & 77.1 & 76.7 & 73.1 \\
& $40 \%$ & 81.3 & 77.4 & 77.4 & 73.2 \\
$\mathrm{E}_{\mathrm{a}}^{\mathrm{a}}$ & $50 \%$ & 81.5 & 77.6 & 78.8 & 73.0 \\
$(\mathrm{~kJ} / \mathrm{mol})$ & $60 \%$ & 81.7 & 78.3 & 78.9 & 72.7 \\
& $70 \%$ & 82.1 & 78.2 & 79.3 & 72.8 \\
& $80 \%$ & 82.0 & 79.0 & 79.6 & 73.2 \\
& $90 \%$ & 82.4 & 81.9 & 81.3 & 74.7 \\
& Average & 80.8 & 78.0 & 77.8 & 73.0 \\
$\mathrm{~A}\left(\mathrm{~s}^{-1}\right)$ & & $4.83 \times 10^{9}$ & $1.66 \times 10^{9}$ & $1.51 \times 10^{9}$ & $4.07 \times 10^{8}$ \\
\hline
\end{tabular}

${ }^{\mathrm{a}}$ The R-value was in the range 0.995-0.999, and the SD was $0.025-0.10$.

to 14 . This may be associated with the lateral chains, which may act like a bound solvent and also facilitate the curing reaction. ${ }^{26}$ The values of frequency factor (A) show the same tendency to $E_{a}$ but change much greater than $E_{a}$ as the side chain length increasing (Table III). This indicated that the curing reaction be- 
Table III. Summary of WAXD results of EP-n

\begin{tabular}{lc}
\hline Sample & $2 \theta(\mathrm{deg})$ \\
\hline EP-2 & 18.32 \\
EP-6 & 18.76 \\
EP-10 & 19.00 \\
EP-14 & 18.84 \\
\hline
\end{tabular}

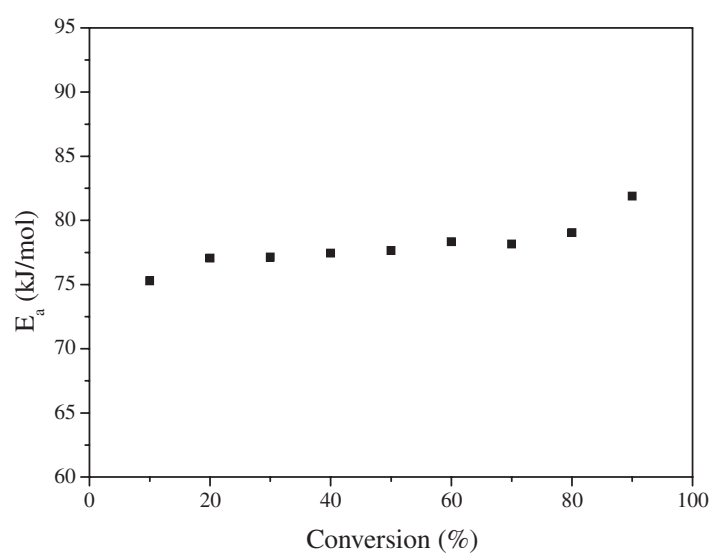

Figure 5. The relationship between activation energy and the fractional conversion for EP-6.

comes less active when the LC epoxides have longer lateral substituents. This could be explained on the basis of steric hindrance of side chains. In fact, long lateral substituents overshadow the end epoxy groups and oppose to the addition of the hardener.

Figure 5 plots the values of the activation energy for different values of conversion, showing $E_{a}$ gradually increase at the early stage of reaction. This may be due to the consumption of the accelerator and decrease of the mobility of the reactive groups of partially cured epoxy. The value of $E_{a}$ is about constant in the interval $20 \%<\alpha<80 \%$. As the cure progresses and the resin cross-links, the mobility of the reaction groups could be hindered, and the rate of curing becomes to be controlled by diffusion.

\section{Structures of cured networks}

While a considerable number of articles have been devoted to the study of structures of LC epoxies-aromatic amine systems, only few works have so far been published on LC epoxies-anhydride systems. ${ }^{25}$

The typical phase of EP-6/MHHPA/BDMA cast from dichloromethane exhibited a typical nematic structure at $355 \mathrm{~K}$ (Figure 6a). After cured at $355 \mathrm{~K}$ for $16 \mathrm{~h}$, it can be seen from Figure $6 \mathrm{~b}$, the structural coarsening proceeded by the growth of the dropletlike domains through domain expansion and/or coalescence. And the nematic structure was fixed by mid- and post-curing. The nematic phase was further confirmed by WAXD result, which showed a broad peak at $2 \theta=18.76^{\circ}$.

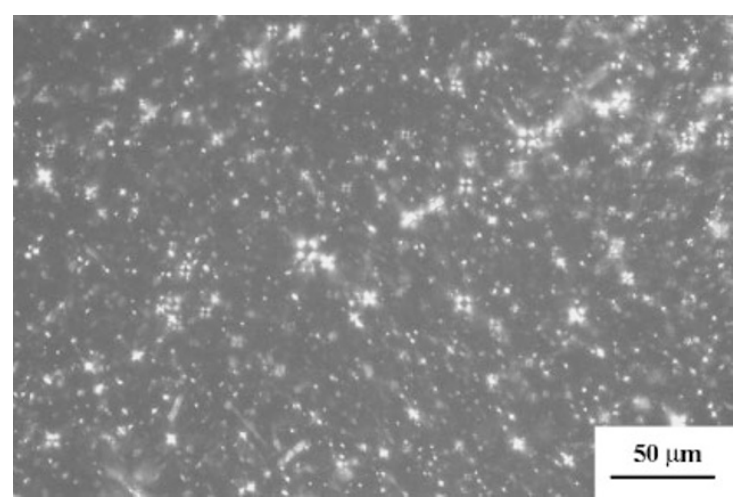

(a)

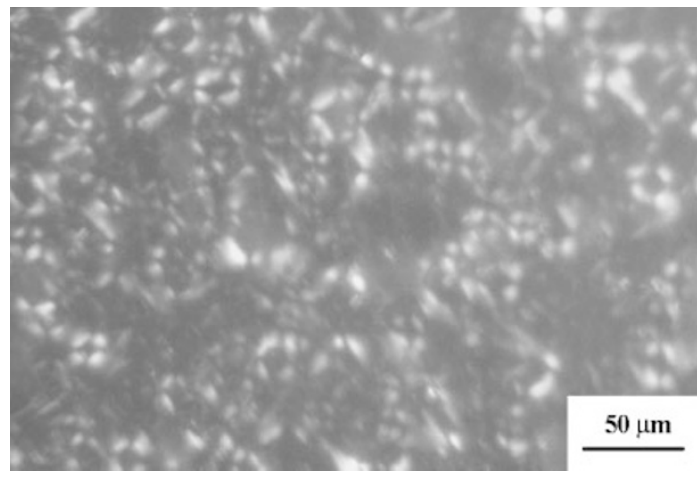

(b)

Figure 6. (a) POM of EP-6/MHHPA/BDMA (at $355 \mathrm{~K}$ ). (b) POM of EP-6/MHHPA/BDMA (after cured at $355 \mathrm{~K}$ for $16 \mathrm{~h}$ ).

The WAXD results of EP-2, EP-10 and EP-14 were similar as EP-6. As can be seen in Table III, the length of lateral substituents has little effect on value of $2 \theta$, implying that the structures of LC phase wouldn't change as the length of lateral substituent increasing.

\section{Dynamic mechanical analysis}

Tan $\delta$ curves as a function of temperature determined for different length of lateral substituents of epoxides are shown in Figure 7. As the length of lateral substituents increases, $T_{g}$ decreases. Table IV presented the comparison of $\mathrm{T}_{\mathrm{g}}$ obtained from DSC and DMA results. The $T_{g}$ values observed from DSC are lower those from DMA but follow the same trend.

Figure 8 shows the dynamic mechanical spectra of loss modulus for different length of lateral substituents of epoxides. A distinct peak is observed at $383 \mathrm{~K}$, representing the glass transition temperature. Another unconspicuous peak is observed at about $193 \mathrm{~K}$, representing the $\beta$-transition temperature. The $\beta$-transition is attributed to the movements of side chain (either bond bending or stretching) or to the localized movement of the glycidyl ether fragments between networks. ${ }^{27}$ The strength of the $\beta$-transition is related to the efficiency of epoxy in absorbing energy, as reflected in mechanical and acoustic properties. ${ }^{28}$ The glass 


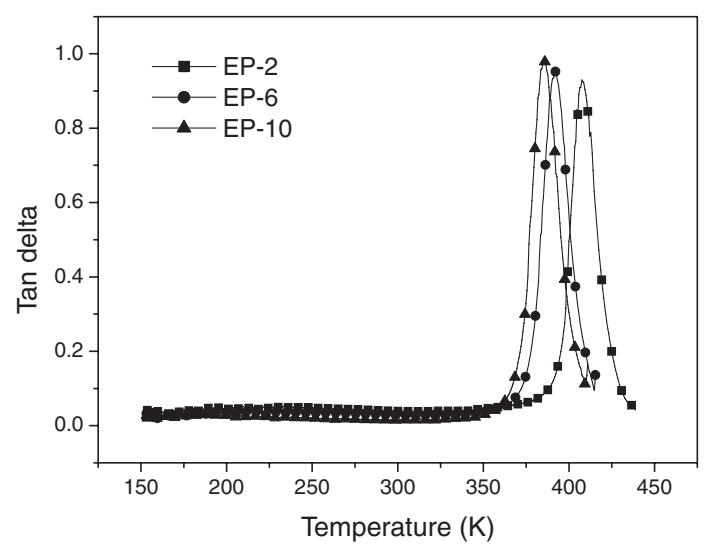

Figure 7. Tan delta as a function of temperature from DMA for EP-n.

Table IV. Comparison of $\mathrm{T}_{\mathrm{g}}$ obtained from DMA and DSC

\begin{tabular}{lcc}
\hline Sample & $\begin{array}{c}\mathrm{T}_{\mathrm{g}} \text { obtained from } \\
\text { DMA }^{\mathrm{a}}(\mathrm{K})\end{array}$ & $\begin{array}{c}\mathrm{T}_{\mathrm{g}} \text { obtained from } \\
\text { DSC }(\mathrm{K})\end{array}$ \\
\hline EP-2 & 407.5 & 392.3 \\
EP-6 & 392.1 & 372.3 \\
EP-10 & 385.3 & 365.6 \\
EP-14 & $/$ & 327.4 \\
\hline
\end{tabular}

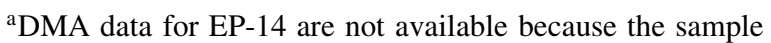
curled up during the glass transition region.

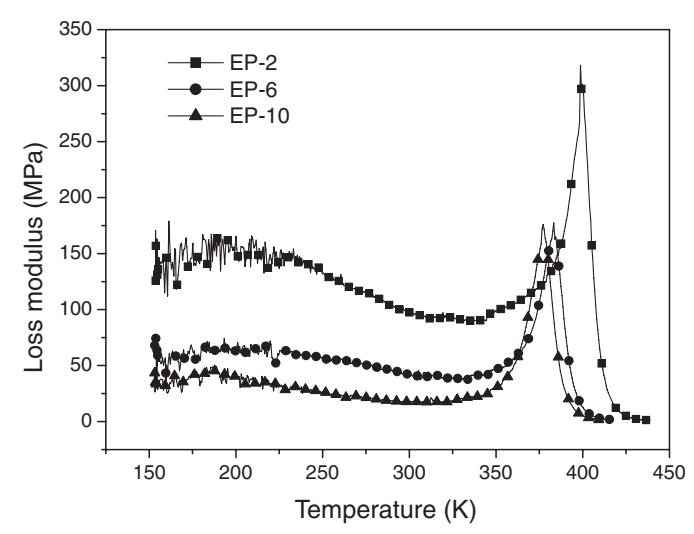

Figure 8. Comparison of loss modulus values for EP-n from DMA.

transition or $\alpha$-transition of cured epoxy is the indication of rotational freedom in the segment between cross-links.

The storage modulus curves for cured epoxies consist of three main regions (Figure 9). One is the glassy region, which has a modulus value above $10^{9} \mathrm{~Pa}$. In the transition region, there is a sudden drop from $10^{9}$ to $10^{7} \mathrm{~Pa}$. The modulus in the rubbery region $\left(E_{R}\right)$ is in the $2 \sim 4 \times 10^{7} \mathrm{~Pa}$ range. As the length of lateral substituents increasing, the storage modulus in the glassy region decreases gradually. This behavior is related to the decrease of the hydrogen bond

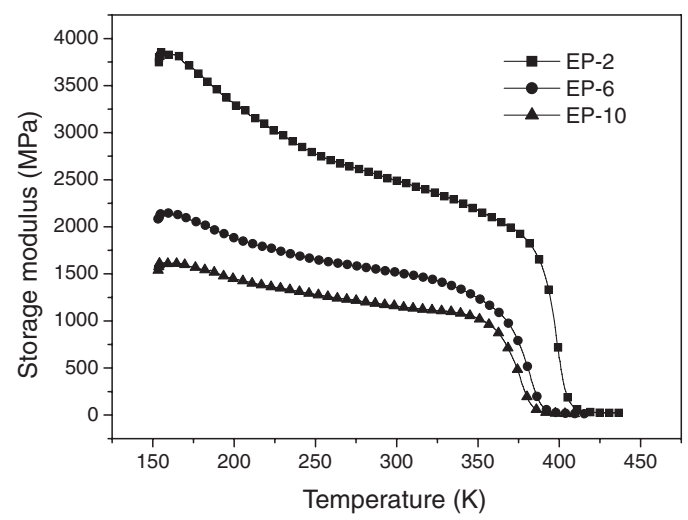

Figure 9. Comparison of storage modulus values for EP-n from DMA.

Table V. Average molecular weight between cross-linking site $(\mathrm{Mc})$ calculated for EP-n

\begin{tabular}{ccccc}
\hline Sample & EP-2 & EP-6 & EP-10 & EP-14 \\
\hline$\rho\left(\mathrm{kg} / \mathrm{m}^{3}\right)$ & 1.102 & 1.074 & 1.054 & 1.051 \\
$\mathrm{E}_{\mathrm{R}}$ & 29.5 & 22.0 & 17.9 & $/$ \\
Mc calcu. & 351 & 379 & 407 & 435 \\
Mc exper. & 388 & 490 & 581 & $/$ \\
\hline
\end{tabular}

and the van der waals interaction, for the spacing of mesogens is related to the length of flexible side chain.

The storage modulus in the plateau region above $T_{g}$ is proportional to the number of crosslinking density or, alternatively, the chain length between entanglements by the following equation. ${ }^{28-30}$

$$
E_{R} \approx(3 \rho R T) / M_{C}
$$

where $\rho$ is the polymer density, which was assumed to be a constant, $\mathrm{R}$ is the gas constant, $T$ is temperature in kelvin, and $M_{c}$ is the molecular weight between cross-linking sites. Thus, the $M_{c}$ values of the final liquid crystalline networks can be calculated from the modulus of the plateau region and are listed in Table V.

Table $\mathrm{V}$ shows that epoxide with longer side chain has larger $M_{c}$, indicating smaller cross-linking densities. This is likely due to the increase of block of side chains with the increase in the length of side chain of epoxides.

\section{Tensile properties}

For conventional epoxy resins, in general, high cross-linking density leads to poor toughness. Much effort was devoted to improve the fracture toughness in the past ten years. Of all the ways, LC epoxy resin is an effective method to realize the aim. ${ }^{9}$

Figure 10 showed that tensile properties are very dependent on the length of lateral substituent. As the length of lateral substituent increases, the tensile mod- 


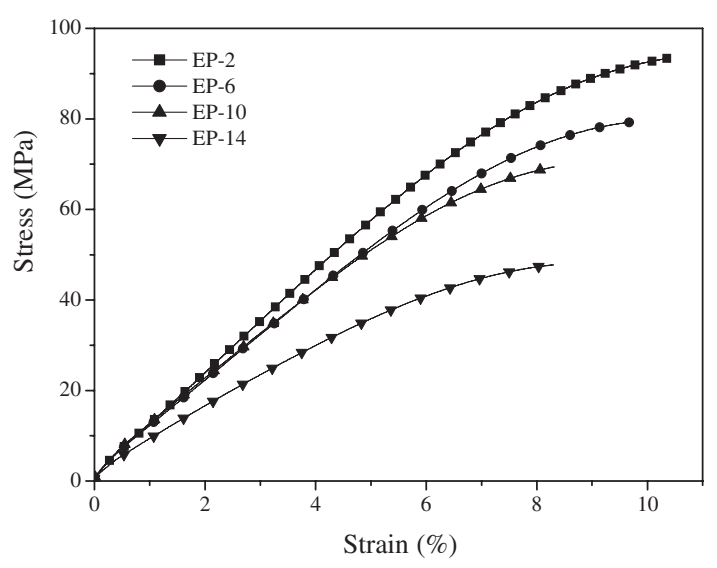

Figure 10. Stress as a function of strain for EP-n.

ulus, together with break strength and elongation at break decreases. The values of tensile modulus corresponded to the storage modulus, and the reason for changes is also the same to the storage modulus. The decrease of break strength and elongation at break are related not only to the cross-linking density but also to the free volume. From Table V, it can be seen that as the length of side chain of epoxides increasing, the polymer density $(\rho)$ decreases, implying more free volume was wrapped into the LCERs. The epoxy network can be easily broken with the increasing free volume. Moreover, as the side chain increasing, the cross-linking density decreases, resulting in low break strength. So both the break strength and the elongation at break decrease as the length of side chain increasing.

\section{Fractography}

The fracture surfaces were investigated by SEM to support the mechanical results. For conventional epoxy resins, the fracture surfaces are always plain. Fracture surfaces of the tensile specimens are showed in Figure 11. It's clear that they are rather rough. Higher surface roughness is connected with higher energy required to fracture the specimens. The microstructure of LC epoxy resin, having overall isotropic properties, consists of anisotropic domains with properties, such as strength, different along and across their molecular orientations. This results in the deviation of crack propagation from a straight line and suggests that inhomogeneities and anisotropic domain of the nematic structure are the main reasons for the fracture toughness increase.

\section{Conclusion}

We studied the cure kinetics of LC epoxy-anhydride system by non-isothermal DSC method. The activation energy $E_{a}$ and the frequency factor $A$ were determined and compared for epoxides with different length of lateral substituents. The activation energy $E_{a}$ obtained from Ozawa methods varies from 73 to $80.8 \mathrm{~kJ} / \mathrm{mol}$ as the lateral substituents increases from 2 to 14 . The curing reaction becomes less active when the LC epoxides have longer lateral substituents, and is controlled by diffusion at the late stage of reaction. The epoxy resins showed a nematic phase when cured with MHHPA. And as the length of lateral substituent increases, the cross-linking densities of the LC networks decreases, resulting decrease of $T_{g}$. The tensile
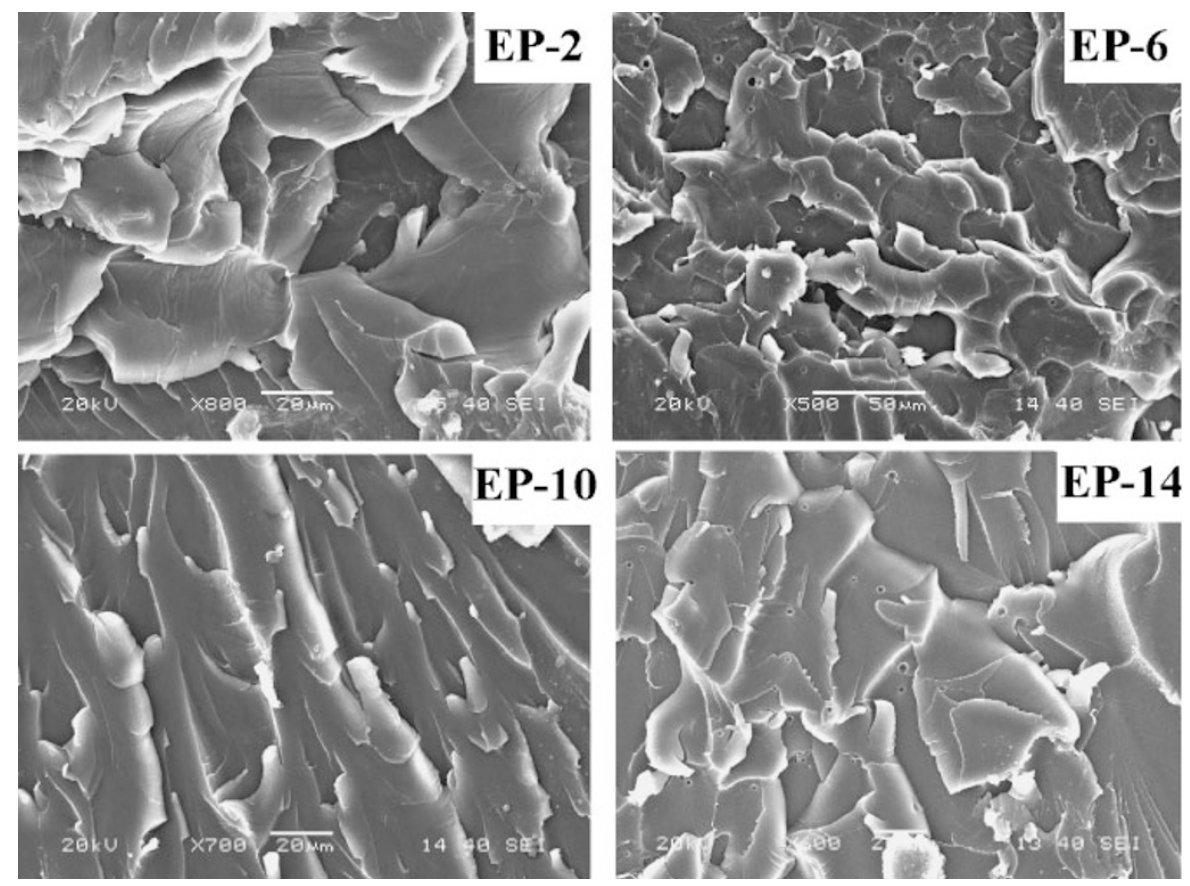

Figure 11. SEM image of fracture surfaces of EP-n. 
modulus, together with break strength and elongation at break also decreases as the side chain increasing.

Acknowledgment. The author would like to thank the National Natural Science Foundation of China (Grant number: 20574072) and Natural Science Foundation of Guangdong Province (Grant number: 04101248) for financial support.

\section{REFERENCES}

1. C. A. May, in "Epoxy Resins: Chemistry and Technology," 2 ed., Marcel Dekker, New York, 1998.

2. G. Wisankrattit and J. K. Gillham, J. Appl. Polym. Sci., 41, 2885 (1990).

3. T. Liyima, S. Miura, W. Fukuda, and M. Tomoi, Eur. Polym. J., 29, 1103 (1993).

4. M. G. Lu, M. J. Shun, and S. W. Kim, Macromol. Chem. Phys., 202, 223 (2001).

5. M. Brehmer and R. Zentel, Mol. Cryst. Liq. Cryst., 243, 353 (1994).

6. E. Amendola, G. Carfagna, M. Giamberini, and G. Pisaniello, Macromol. Chem. Phys., 196, 1577 (1995).

7. C. Ortiz, R. Kim, E. Rodighiero, C. K. Ober, and E. J. Kramer, Macromolecules, 31, 4074 (1998).

8. M. Giamberini, E. Amendola, and C. Carfagna, Mol. Cryst. Liq. Cryst., 266, 9 (1995).

9. C. Carfagna, E. Amendola, and M. Giamberini, Prog. Polym. Sci., 22, 1607 (1997).

10. J. Y. Lee and J. Jang, J. Polym. Sci., Part A: Polym. Chem., 22, 911 (1998).

11. W. Mormann, M. Bröcher, and P. Schwarz, Macromol. Chem. Phys., 198, 3615 (1997).
12. H. J. Sue, J. D. Earls, and R. E. Hefner, J. Mater. Sci., 32, 4039 (1997).

13. M. G. Lu and S. W. Kim, J. Appl. Polym. Sci., 71, 2401 (1999).

14. "Liquid Crystalline Polymers: Chemistry, Structure and Properties," R. Weiss and C. K. Ober, Ed., American Chemical Society, Washington, DC, 1990.

15. K. J. Jaunder, in "Organic Polymer Chemistry," Chapman \& Hall, London, 1973.

16. Y. Q. Zheng, M. M. Shen, M. G. Lu, and S. P. Ren, Eur. Polym. J., 42, 1735 (2006).

17. S. Vyazovkin and N. Sbirrazzuoli, Macromolecules, 29, 1867 (1996).

18. N. Sbirrazzuoli and S. Vyazovkin, Thermochim. Acta, $\mathbf{3 8 8}$, 289 (2002).

19. T. Ozawa, Bull. Chem. Soc. Jpn., 38, 1881 (1965).

20. J. H. Flynn, J. Therm. Anal., 27, 95 (1983).

21. L. D. Doyle, Nature, 207, 290 (1965).

22. F. Y. C. Boey and W. Qiang, Polymer, 41, 2081 (2000).

23. S. Montserrat, C. Flaqué, P. Pagés, and J. Málek, J. Appl. Polym. Sci., 56, 1413 (1995).

24. S. Montserrat, C. Flaqué, M. Calafell, G. Andreu, and J. Málek, Thermochim. Acta, 269, 213 (1995).

25. P. Punchaipetch, V. Ambrogi, and M. Giamberini, Polymer, 42, 2067 (2001).

26. E. J. Choi, J. C. Seo, H. K. Bae, and J. K. Lee, Eur. Polym. J., 40, 259 (2004).

27. D. E. Kline, J. Polym. Sci., 47, 237 (1960).

28. K. P. Menard, in "Dynamic Mechanical Analysis: A Practical Introduction," CRC Press, Boca Raton, 1999.

29. J. A. Schroeder, P. A. Madsen, and R. T. Foister, Polymer, 28, 929 (1987).

30. M. Hidalgo, H. Reinecke, and C. Mijangos, Polymer, 40, 3535 (1999). 